\title{
Incidence and Multiplicities of Adenomatous Polyps in TNM Stage I Colorectal Cancer in Korea
}

\author{
Young-Sang Hong, Eun-Joo Jung, Chun-Geun Ryu, Gang-Mi Kim, Su-Ran Kim, Sung-Noh Hong ${ }^{1}$, \\ Dae-Yong Hwang
}

Department of Surgery, Colorectal Cancer Center, ${ }^{1}$ Department of Internal Medicine, Konkuk University Medical Center, Konkuk University School of Medicine, Seoul, Korea

Purpose: In recent years, the incidence of early-stage colorectal cancer (CRC) has markedly increased in the population within the Republic of Korea. The aim of this study was to evaluate the clinicopathologic features of adenomatous polyps in TNM stage I CRC patients and in the general population.

Methods: Between March 2003 and September 2009, 168 patients with stage I CRC were enrolled in this study. In addition, the records of 4,315 members of the general population without CRC, as determined by colonoscopy during a health checkup, were reviewed.

Results: Of the 168 patients with stage I CRC, $68(40.5 \%)$ had coexisting colorectal adenomatous polyps and of the 4,315 members of the general population, $1,112(26.0 \%)$ had coexisting adenomatous polyps $(\mathrm{P}=0.006)$. The prevalences of adenomatous polyp multiplicity in early CRC and in the general population were $32 \%$ and $15 \%$, respectively $(\mathrm{P}=0.023)$. $\mathrm{Pa}$ tients with coexisting adenomatous polyps had a higher frequency of tubulovillous or villous adenomas than members of the general population with polyps $(7.5 \%$ vs. $2.0 \%, \mathrm{P}=0.037)$. Furthermore, a subgroup analysis showed that the occurrence $(44 \%$ vs. $34 \%, \mathrm{P}=0.006)$ and the multiplicity $(32 \%$ vs. $15 \%, \mathrm{P}=0.023)$ of adenomatous polyps were greater for $\mathrm{T} 2$ than $\mathrm{T} 1$ cancer.

Conclusion: The prevalence and the multiplicity of adenomatous polyps in TNM stage I CRC is higher than it is in the general population. The findings of this study suggest that depth of invasion of early stage CRC affects the prevalence and the number of adenomatous polyps in the remaining colon and rectum.

\section{Keywords: Colorectal carcinoma; Adenomatous polyp; Stage I; Colonoscopy}

\section{INTRODUCTION}

The incidence of colorectal cancer (CRC) is increasing worldwide, and this trend has raised concerns among health professionals. As a result, screening surveillance for CRC is now conducted in the

Received: June 24,2012 - Accepted: July 16, 2012

Correspondence to: Dae-Yong Hwang, M.D.

Department of Surgery, Colorectal Cancer Center, Konkuk University Medical Center, Konkuk University School of Medicine, 120 Neungdong-ro,

Gwangjin-gu, Seoul 143-729, Korea

Tel: +82-2-2030-5111, Fax: +82-2-2030-5112

E-mail: hwangcrc@kuh.ac.kr

(c) 2012 The Korean Society of Coloproctology

This is an open-access article distributed under the terms of the Creative Commons Attribution NonCommercial License (http://creativecommons.org/licenses/by-nc/3.0) which permits unrestricted noncommercial use, distribution, and reproduction in any medium, provided the original work is properly cited. general population. This increased examination has markedly increased the number of asymptomatic patients requiring treatment for early stage CRC. According to a study conducted by Choi et al. [1] in 2006, tumor-node-metastasis (TNM) stage I CRC accounts for about $20 \%$ of all CRC patients in Korea, and this proportion is 1.5 -fold higher than the 13\% reported in 1999. Furthermore, the prognosis of TNM stage I CRC is excellent, with a 5-year survival rate of over $90 \%$.

The adenoma-carcinoma sequence of mutagenic events is a popular hypothesis for carcinogenesis in CRCs. More than $85 \%$ of diagnosed CRCs have been demonstrated to arise from adenomas, and the adenomatous polyp rate among CRC patients has been shown to be higher than it is in the general population without CRC [2-11]. Even though most early stage CRCs develop from adenomatous polyps, few studies have compared the clinical characteristics of polyps, such as their multiplicity and histology in 
early stage CRC patients and in the general populations. In addition, little evidence is available on the relationship between neoplastic polyp prevalence or multiplicities and tumor progression, although several studies have reported no evidence to suggest a correlation between the CRC stage and the prevalence of neoplastic polyps $[7,12]$. Therefore, this study was designed to compare the clinicopathologic features of adenomatous polyps in patients with TNM stage I CRC with those of adenomatous polyps in the general population in Korea.

\section{METHODS}

Between March 2003 and September 2009, 168 patients after curative resection were diagnosed at our institute with a TNM stage I colorectal adenocarcinoma. Rectal cancer patients who had undergone a transanal excision and those with hereditary CRC, such as familial adenomatous polyposis or hereditary non-polyposis CRC, were excluded from the analysis. This analysis was conducted using information contained in a prospectively collected CRC database at our institute. CRC staging was performed as described by the American Joint Cancer Committee (7th. edition) [13]. Stage I is composed of T1N0M0 and T2N0M0. Tumor depth is limited to the submucosa for T1 lesions and to the muscularis propria for T2 lesions. Non-neoplastic polyps, such as inflammatory polyps or hyperplastic polyps, were excluded. Only adenomatous polyps, defined as tubular, tubulovillous and villous adenoma, were included in this study. For comparison purposes, the data of 4,315 members of the general population without CRC as determined by colonoscopy during a routine health check-up during the same period were reviewed.

Data analysis was performed using the SPSS ver. 14.0 (SPSS Inc., Chicago, IL, USA). Summary statistics were compared using the two-sample t-test, and Pearson's chi-squared test was used to compare subgroups. P-values of $<0.05$ were considered statistically significant.

\section{RESULTS}

One hundred one males and 67 females, mean age of 59.8 years (range, 28 to 85 years), were included. Seventy-five patients (44.6\%) had colon cancer, and 93 patients (55.4\%) had rectal cancer; 56 patients $(33.3 \%)$ had T1N0M0 cancer (T1 group), and 112 patients $(66.7 \%)$ had T2N0M0 cancer (T2 group). Of the 75 patients with colon cancer, 36 patients $(48.0 \%)$ were in the T1 group, and 39 patients (52.0\%) were in the T2 group. Of the 93 patients with rectal cancer, 20 patients $(21.5 \%)$ were in the $\mathrm{T} 1$ group, and 73 patients $(78.5 \%)$ were in the T2 group. The proportion of rectal cancer in the T2 group (65.2\%) was higher than it was in the T1 group (35.7\%, $\mathrm{P}<0.001)$. The clinicopathologic characteristics of patients in the T1 and the T2 groups are shown in Table 1.

The mean tumor size was larger in the T2 group than in the T1 group ( $3.6 \mathrm{~cm}$ vs. $2.7 \mathrm{~cm}, \mathrm{P}=0.039$ ), but no significant difference was found for other variables, including gender, age, preoperative CEA and CA19-9 levels, prevalence of an elevated CEA or CA 19-9 level, tumor histologic differentiation, and lymphatic, perineural, or vascular invasion. Preoperative colonoscopic examinations in patients with $\mathrm{T} 1$ or $\mathrm{T} 2$ stage $\mathrm{CRC}$ revealed that 68 patients (40.5\%) had coexisting adenomatous polyps. Furthermore, the prevalence of coexisting adenomatous polyps was higher in the T2 group than it was in the T1 group ( $43.8 \%$ vs. $33.9 \%, \mathrm{P}=0.014$ ). A tubular adenoma was the most common type in both groups. These data are summarized in Table 2. Fifteen patients (78.9\%) with a coexisting polyp in the T1 group and $31(63.3 \%)$ in the T2 group had either a single or two adenomatous polyps. The prevalence of three or more adenomatous polyps was significantly higher in the $\mathrm{T} 2$ group $(36.7 \%)$ as compared to the $\mathrm{T} 1$ group $(21.1 \%, \mathrm{P}=$ 0.017) (Table 3).

In TNM stage I CRC, the prevalence of tubular adenomas was

Table 1. Patient characteristics

\begin{tabular}{|c|c|c|c|}
\hline Characteristic & $\begin{array}{l}\text { T1N0M0 } \\
(n=56)\end{array}$ & $\begin{array}{l}\text { T2NOM0 } \\
(\mathrm{n}=112)\end{array}$ & P-value \\
\hline $\operatorname{Sex}(\mathrm{M}: \mathrm{F})$ & $33: 23$ & $68: 44$ & 0.824 \\
\hline Age (yr) & $61.3 \pm 9.4$ & $59.0 \pm 11.1$ & 0.189 \\
\hline Colon:rectum (\% of rectum) & $36: 20(35.7)$ & $39: 73(65.2)$ & 0.000 \\
\hline \multicolumn{4}{|l|}{ Location of tumor } \\
\hline Cecum & 8 & 3 & \\
\hline Ascending colon & 5 & 10 & \\
\hline Hepatic flexure & 3 & 0 & \\
\hline Transverse colon & 2 & 0 & \\
\hline Descending colon & 2 & 0 & \\
\hline Sigmoid colon & 7 & 19 & \\
\hline Rectosigmoid & 9 & 7 & \\
\hline Upper rectum & 16 & 45 & \\
\hline Lower rectum & 4 & 27 & \\
\hline Anal canal & 0 & 1 & \\
\hline No. of patients with high CEA & $6(10.7)$ & $9(8.0)$ & 0.452 \\
\hline No. of patients with high CA 19-9 & $2(3.6)$ & $3(2.7)$ & 0.697 \\
\hline Tumor size (cm) & $2.7 \pm 1.6$ & $3.6 \pm 1.5$ & 0.039 \\
\hline Tumor cell differentiation & & & 0.405 \\
\hline Well-differentiated & 20 & 47 & \\
\hline Moderately-differentiated & 33 & 63 & \\
\hline Poorly-differentiated & 1 & 0 & \\
\hline Mucinous & 2 & 2 & \\
\hline \multicolumn{4}{|l|}{ Tumor cell invasion } \\
\hline Lymphatic invasion & $8(14.2)$ & $14(12.5)$ & 0.830 \\
\hline Perineural invasion & $0(0)$ & $3(2.7)$ & 0.414 \\
\hline Vascular invasion & $0(0)$ & $2(1.8)$ & 0.534 \\
\hline
\end{tabular}

Values are presented as mean \pm SD or number (\%). 
92.5\%, of tubulovillous adenomas was $6.3 \%$, and of villous adenomas was $1.3 \%$ (Fig. 1A). Of the patients in the T1 group, 95.2\% had a tubular adenoma and $4.8 \%$ had a tubulovillous adenoma, and in the T2 group, $91.5 \%$ had a tubular adenoma, $6.8 \%$ had a tubulovillous adenoma, and $1.7 \%$ had a villous adenoma (Fig. 1B). Of patients with TNM stage I CRC, those with one or two polyps had tubular adenoma and tubulovillous adenoma occurrence rates of $95.2 \%$ and $4.8 \%$, respectively, and of those with three or more polyps, the tubular adenoma, tubulovillous adenoma, and villous adenoma occurrence rates were reported as $90.7 \%, 7.2 \%$, and $2.1 \%$, respectively.

Comparing the data from stage I CRC patients with those of the 4,315 members of the general population without CRC, the prevalence of adenomatous polyps was found to be significantly higher

Table 2. Prevalence of coexisting adenomatous polyps based on preoperative colonoscopic examinations in patients with TNM stage I CRC

\begin{tabular}{lccc}
\hline & $\begin{array}{c}\text { T1 group } \\
(\mathrm{n}=56)\end{array}$ & $\begin{array}{c}\text { T2 group } \\
(\mathrm{n}=112)\end{array}$ & P-value \\
\hline No polyp & $37(66.1)$ & $63(56.3)$ & 0.014 \\
Adenomatous polyp & $19(33.9)$ & $49(43.8)$ & \\
\hline
\end{tabular}

Values are presented as number (\%).

TNM, tumor-node-metastasis; CRC, colorectal cancer. in stage I CRC than in the general population ( $40 \%$ vs. $26 \%, \mathrm{P}=$ 0.006). In addition, the prevalence of patients with multiple adenomatous polyps was also significantly higher in stage I CRC (32\%) than in the general population $(15 \%, \mathrm{P}=0.023)$. By subgroup analysis, the prevalence of adenomatous polyps was $34 \%$ in the $\mathrm{T} 1$ group, $44 \%$ in the T2 group, and $26 \%$ in the general population ( $\mathrm{P}$

Table 3. Distributions of adenomatous polyps by number in TNM stage I CRC

\begin{tabular}{lcc}
\hline No. of adenomatous polyps & T1 group $(\mathrm{n}=19)$ & T2 group $(\mathrm{n}=49)$ \\
\hline 1 & $8(42.1)$ & $22(44.9)$ \\
2 & $7(36.8)$ & $9(18.4)$ \\
Sub total & $15(78.9)$ & $31(63.3)$ \\
3 & $1(5.3)$ & $6(12.2)$ \\
4 & $1(5.3)$ & $6(12.2)$ \\
5 & $1(5.3)$ & $3(6.1)$ \\
6 & $0(0)$ & $1(2.0)$ \\
7 & $0(0)$ & $2(4.1)$ \\
8 & $1(5.3)$ & $0(0)$ \\
Sub total & $4(21.1)$ & $18(36.7)$ \\
\hline
\end{tabular}

Values are presented as number (\%).

TNM, tumor-node-metastasis; CRC, colorectal cancer.

Table 4. Comparison of the prevalence of adenomatous polyps in stage I colorectal cancer (CRC) patients and in the general population

\begin{tabular}{|c|c|c|c|c|c|c|}
\hline Prevalence & General population & Stage I CRC & $\mathrm{P}$-value ${ }^{\mathrm{a}}$ & T1 group & T2 group & $\mathrm{P}^{\text {-value }}{ }^{\mathrm{b}}$ \\
\hline Adenomatous polyp & $1,112 / 4,315(26)$ & 68/168 (40) & 0.006 & 19/56 (34) & 49/112 (44) & 0.008 \\
\hline $\begin{array}{l}\text { Multiple adenomatous polyps, } \\
\text { no. of polyps } \geq 3\end{array}$ & $172 / 1,112(15)$ & 22/68 (32) & 0.023 & $4 / 19(21)$ & $18 / 49(37)$ & 0.034 \\
\hline
\end{tabular}

Values are presented as number (\%).

${ }^{\mathrm{a} G e n e r a l ~ p o p u l a t i o n ~ v s . ~ s t a g e ~ I ~ C R C . ~}{ }^{\mathrm{b}} \mathrm{T} 1$ group vs. T2 group.
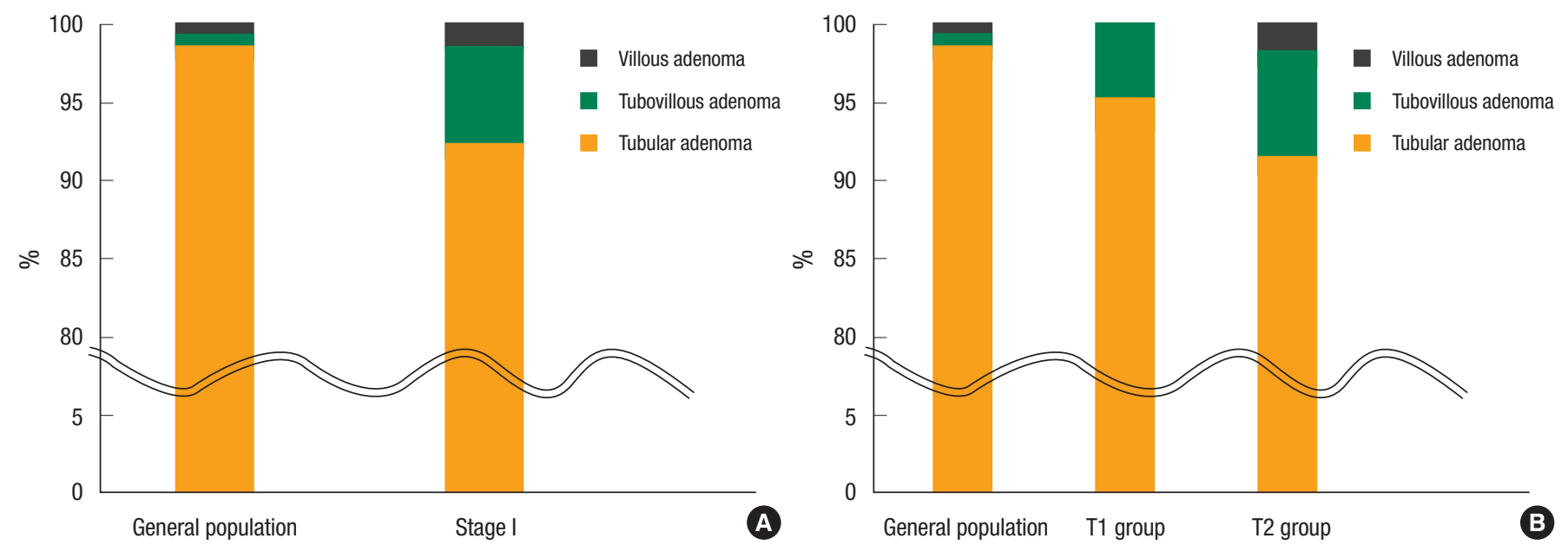

Fig. 1. Proportions of adenomatous polyps by pathologic findings: (A) general population $v s$. stage I colorectal cancer patients and (B) general population vs. the $\mathrm{T} 1$ and the $\mathrm{T} 2$ groups. 
Table 5. Pathologies of associated polyps in stage I colorectal cancer (CRC) patients and in the general population

\begin{tabular}{|c|c|c|c|c|c|c|}
\hline No. of polyps & $\begin{array}{l}\text { General population } \\
\quad(n=1,778)\end{array}$ & $\begin{array}{l}\text { Stage I CRC } \\
(n=159)\end{array}$ & P-value ${ }^{a}$ & $\begin{array}{l}\text { T1 group } \\
(\mathrm{n}=42)\end{array}$ & $\begin{array}{l}\text { T2 group } \\
(\mathrm{n}=117)\end{array}$ & P-value ${ }^{b}$ \\
\hline Tubular & $1,751(98.5)$ & 147 (92.5) & 0.037 & 40 (95.2) & 107 (91.5) & 0.048 \\
\hline Tubulovillous & $16(0.9)$ & $10(6.3)$ & & $2(4.8)$ & $8(6.8)$ & \\
\hline Villous & $11(0.6)$ & $2(1.3)$ & & $0(0)$ & $2(1.7)$ & \\
\hline
\end{tabular}

Values are presented as number (\%).

${ }^{\mathrm{a}}$ General population vs. stage I CRC. ${ }^{\mathrm{b}} \mathrm{T} 1$ group vs. T2 group.

$=0.008)$. The frequency of multiple adenomatous polyps was $21 \%$ in the $\mathrm{T} 1$ group, $37 \%$ in the T2 group, and $15 \%$ in the general population ( $P=0.034)$, and differences between the groups were statistically significant (Table 4).

The results of the comparison between the pathologies of adenomatous polyps in the general population and in the stage I CRC group are shown in Table 5. Stage I CRC patients with a coexisting adenomatous polyp were found to have a lower incidence of tubular adenomas and a higher occurrence of tubulovillous or villous adenomas as compared to the general population. That is, patients with stage I CRC had a higher frequency of adenomas with a villous component than members of the general population. In the general population, $98 \%$ had a tubular adenoma and $2 \%$ had a tubulovillous or a villous adenoma, and in stage I CRC, $92.5 \%$ of the patients had a tubular adenoma and $7.5 \%$ had a tubulovillous or a villous adenoma $(P=0.037)$. Fig. $1 \mathrm{~A}$ summarizes the observed pathologic differences between adenomatous polyps in the general population and those in stage I CRC. Fig. 1B summarizes the comparison between the general population and both the $\mathrm{T} 1$ and the T2 groups. The prevalence of a coexisting polyp with a villous component was found to be $1.5 \%$ in the general population, $4.8 \%$ in the $\mathrm{T} 1$ group, and $9.1 \%$ in the $\mathrm{T} 2$ group $(\mathrm{P}=0.048)$.

Of the 4,315 members of the general population, 1,112 had adenomatous polyps. These were divided into two groups: the group with one or two polyps and the group with three or more polyps. Of the 1,142 polyps in individuals with one or two polyps, 1,119 (98.0\%) had tubular adenomas, 14 (1.2\%) had tubulovillous adenomas, and only $9(0.8 \%)$ had villous adenomas. Of the 636 polyps found in individuals with three or more polyps, 632 (99.4\%) had tubular adenomas, $2(0.3 \%)$ had tubulovillous adenomas, and $2(0.3 \%)$ had villous adenomas. No significant differences in polyp pathologies were observed between stage I CRC patients and the general population regardless of multiplicity $(\mathrm{P}=0.631)$.

\section{DISCUSSION}

Our results demonstrate that the prevalence and the multiplicity of adenomatous polyps in patients with TNM stage I CRC were higher than they were in the general population and that depth of tumor invasion was associated with a higher prevalence of polyps with a villous component. The adenoma-carcinoma sequence is a well-known hypothesis that explains the carcinogenesis of CRC, and $85 \%$ of CRCs have been suggested to arise from adenomas [2, $7,10,14,15]$. Furthermore, a larger polyp size (1 cm or larger) and more advanced histologic features (tubulovillous or villous) are known to be independent risk factors for the transformation to CRC [15]. In a survey that compared adenoma prevalence and cancer incidence, the percentage of polyps that underwent a transformation to cancer was shown to be approximately $0.25 \%$ per year [14]. Wasif et al. [10] found that individuals with untreated adenomatous polyps developed CRC at a rate of $4 \%$ after 5 years and $14 \%$ after 10 years, which was higher than that observed in the general population. For these reasons, adenomatous polyps are considered an integral part of the carcinogenesis of CRC. Therefore, regular colonoscopic surveillance is recommended in the general population, and polyps found should be removed endoscopically for diagnosis and treatment. In addition, regular colonoscopy has been suggested by the National Comprehensive Cancer Network for the early detection and treatment of adenomatous polyps or recurrence in CRC patients [16]. Thus, the removal of adenomatous polyps has become an important method for the prevention and treatment of CRC $[6,10]$.

Regarding the proportion of rectal cancer patients included in our analysis, transanal local excision could be another treatment option for early rectal cancer without node metastasis, such as T1N0M0, that had been evaluated by preoperative magnetic resonance imaging or endorectal ultrasonography. Many reports have demonstrated that transanal excision can be performed for rectal cancer with characteristics including a T1 lesion, no lymph-node metastasis, a low-grade tumor, a tumor location within $6 \mathrm{~cm}$ of the anal verge, and a tumor without lymphovascular or perineural invasion by biopsy. However, a local excision is not usually recommended nor is it performed in high-risk patients due to the reported incidence of lymphatic spread in up to $15 \%$ of T2 tumors [14]. Because we excluded patients who underwent a transanal local excision, the prevalence of rectal cancer and the tumor size in the T2 group were greater than they were in the T1 group.

In general, the incidence of coexisting adenomatous polyps in CRC patients has been reported to be 15 to $50 \%$ [7, 8]. In Korea, the reported frequencies of adenomatous polyps associated with CRC are approximately 26\% according to Park [7] and 46\% according to Cho et al. [12], which correlates well with our observed incidence of $40 \%$. In addition, it is well accepted that the incidence of adenomatous polyps in CRC patients is higher than in the gen- 
eral population $[6,8,9,11,12]$. In the present study, 4,314 individuals with no evidence of CRC by colonoscopic examination were included in the analysis. The prevalence of adenomatous polyps in this population was $26 \%$, which correlates well with previous reports $[6-9,11,12]$. The prevalence of adenomatous polyps in CRC patients was higher than that in the general population, which is also in-line with previous reports. In other words, the prevalence of adenomatous polyps and the proportion of multiple polyps $(>3)$ were higher in TNM stage I CRC patients than they were in the general population.

However, the present study reveals a substantially different histologic distribution of adenomatous polyps. In the Surveillance Epidemiology and End Results database, the prevalence of tubular adenomas in CRC patients (all stages) is $38 \%$, and those of tubulovillous and villous adenomas are $40 \%$ and $22 \%$, respectively [10]. According to a report issued by Cho et al. [12], the prevalence of tubular adenomas in CRC patients (all stages, but mainly stage II or III) is $84.1 \%$, and tubulovillous and villous adenomas account for 15.2 and $0.7 \%$, respectively. In addition, no significant correlation was found between the frequency of adenomatous polyps in CRC patients and the primary tumor stage, the preoperative CEA levels or the primary tumor sizes [12]. Park [7] also concluded that the primary tumor stage and the adenomatous polyp prevalence were unrelated. Nevertheless, according to our data for TNM stage I CRC, the incidence of adenomatous polyps with a villous component was remarkably lower than that previously reported for all stages of CRC (7.5\% vs. 15.9 to $62.0 \%$ ). Despite the observations of other previous reports, this difference suggests that the frequency of tubulovillous and villous adenomas depends on the TNM stage, leading to the conclusion that no significant correlation exists between the prevalence of adenomatous polyps in CRC and the primary tumor stage $[7,12]$.

In addition, multiple polyps $(>3)$ in CRC have been shown to increase the risk of developing a coexisting advanced polyp and potentially cancer [18]. Bae et al. [2] reported that multiple polyps had greater malignant potential than a single polyp in the general population, suggesting that multiplicity is related to malignant potential in CRC and in the general population. Our results demonstrate that the prevalence of multiple polyps is higher in TNM stage I CRC patients than it is in the general population. Furthermore, the prevalence of multiplicity was found to be positively associated with tumor invasion depth, which suggests that polyp multiplicity is associated with a more advanced T stage.

In summary, the prevalence and the multiplicity of associated adenomatous polyps were found to be higher in the T2N0M0 group than in the T1N0M0 group and to be significantly higher in both of these groups than in the general population. These results clearly establish that increased consideration be given to associated adenomatous polyps even in the case of TNM stage I CRC.

\section{CONFLICT OF INTEREST}

No potential conflict of interest relevant to this article was reported.

\section{REFERENCES}

1. Choi PW, Jung SH, Kim JR, Yu CS, Kim HC, Kim JC. Trend of clinicopathologic characteristics of colorectal cancer in Asan Medical Center: a 15-year experience. J Korean Soc Coloproctol 2006; 22:387-395.

2. Bae TS, Jung KH, Lee JH, Oh MG, Chung BO, Bae SH, et al. Clinical significance of the colorectal polyps. J Korean Soc Coloproctol 2000;16:247-53.

3. Hassan C, Pickhardt PJ, Kim DH, Di Giulio E, Zullo A, Laghi A, et al. Systematic review: distribution of advanced neoplasia according to polyp size at screening colonoscopy. Aliment Pharmacol Ther 2010;31:210-7.

4. Lee JE, Yoon SJ, Ahn EJ, Chung SS,Lee RA, Kim KH, et al. Distribution and characteristics of colorectal polyps at colonoscopy. J Korean Soc Coloproctol 2006;4:223-8.

5. Lee KH, Kim HC, Yu CS, Myung SJ, Yang SG, Kim JC. Colonoscopic surveillance after curative resection for colorectal cancer with synchronous adenoma. Korean J Gastroenterol 2005;46:381-7.

6. Bujanda L, Cosme A, Gil I, Arenas-Mirave JI. Malignant colorectal polyps. World J Gastroenterol 2010;16:3103-11.

7. Park YJ. Synchronous lesions in colorectal cancer. J Korean Soc Coloproctol 2005;21:413-8.

8. Regula J, Rupinski M, Kraszewska E, Polkowski M, Pachlewski J, Orlowska J, et al. Colonoscopy in colorectal-cancer screening for detection of advanced neoplasia. N Engl J Med 2006;355:1863-72.

9. Saini SD, Kim HM, Schoenfeld P. Incidence of advanced adenomas at surveillance colonoscopy in patients with a personal history of colon adenomas: a meta-analysis and systematic review. Gastrointest Endosc 2006;64:614-26.

10. Wasif N, Etzioni D, Maggard MA, Tomlinson JS, Ko CY. Trends, patterns, and outcomes in the management of malignant colonic polyps in the general population of the United States. Cancer 2011;117:931-7.

11. Winawer SJ, Zauber AG, Fletcher RH, Stillman JS, O’Brien MJ, Levin B, et al. Guidelines for colonoscopy surveillance after polypectomy: a consensus update by the US Multi-Society Task Force on Colorectal Cancer and the American Cancer Society. Gastroenterology 2006;130:1872-85.

12. Cho JH, Lee SK, Kim TI, Kim WH. Characteristics and risk factors of synchronous and metachronous polyp in colorectal cancer. Korean J Gastroenterol 2004;43:168-75.

13. Edge SB, Byrd DR, Compton CC, Fritz AG, Greene FL, Trotti A. AJCC cancer staging manual. 7th ed. New York: Springer; 2010.

14. Gordon PH, Nivatvongs S. Principles and practice of surgery for the colon, rectum, and anus. New York: Informa Healthcare; 2006.

15. Levine JS, Ahnen DJ. Clinical practice: adenomatous polyps of the colon. N Engl J Med 2006;355:2551-7. 


\section{Coloproctology Young-Sang Hong, et al.}

16. NCCN.com [Internet]. Fort Washington: National Comprehensive Cancer Network; c2012 [cited 2012 Mar 3]. NCCN guideline for patients: colon cancer. Available from http://www.nccn.com/ files/cancer-guidelines/colon/index.html.

17. Chang DK. Endoscopic diagnosis and treatment of colorectal cancers. J Korean Med Assoc 2010;53:549-61.

18. Costedio M, Church J. Pathways of carcinogenesis are reflected in patterns of polyp pathology in patients screened for colorectal cancer. Dis Colon Rectum 2011;54:1224-8. 